\title{
Analysis of Steam Injector and Sparger
}

\author{
D. Walunje, Rajiv B. \\ (Department Of Production Engineering And Industrial Management, College Of Engineering, Pune)
}

\begin{abstract}
A comparative study of steam injector \& steam sparger is undertaken regarding heating of constant volume of water by keeping the structure rigid at all times. Vibrations in the structure are then monitored with the help of accelerometer \& dial gauge. Homogeneous heating of water was also studied by noting down temperatures at different locations of the tank with the help of data logger. The data obtained is then compiled $\&$ the range of temperatures for which vibrations in the structure occurs more \& the least are obtained. Hence, the performance of steam injector \& steam sparger is effectively compared.
\end{abstract}

Keywords: Steam injection, vibrations, sparger

\section{Introduction}

Steam injector is used in industry for boiler feed water heating applications. The feed water is heated to remove oxygen from it. From Henry Dalton's law, the solubility of air is inversely proportional to temperature of the water. Thus, increasing temperature of the water results in removal of dissolved air from the water. The steam injector consists of steam nozzle, a water nozzle and mixing chamber. When steam flows out of the steam nozzle it creates a vacuum, resulting in suction of water in the mixing chamber. The water mixes with steam in the mixing chamber resulting in condensation of steam and heating of the water. This process accompanied by the high heat transfer coefficient. The condensation of steam is smooth till water reaches a temperature of $90^{\circ} \mathrm{C}$. After $90^{\circ} \mathrm{C}$ with some sizes of steam injector heavy vibrations are observed in the structure. This study is carried out to understand and reduce these vibrations.

\section{Experimental Setup}

An experimental setup was constructed to study the steam injector and the spargers. Figure 1 shows the schematic of the experimental setup.

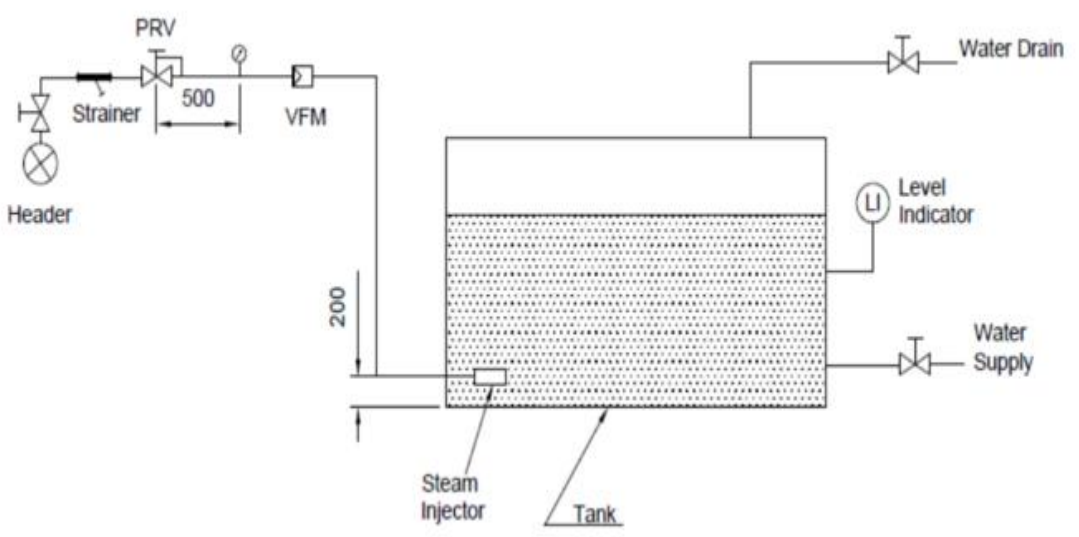

Fig. 1 Experimental Setup

It consists of a pressure vessel of volume $1.71 \mathrm{~m}^{3}$. The overall dimensions of the tank are $1.28 \mathrm{~m}$ by $1.7 \mathrm{~m}$. The water is filled up to a required level with the help of level indicator. The steam line consists of PRV to reduce pressure and the vortex flowmeter to measure the flow. The steam can be injected into tank with the help of steam injector or sparger. The temperature of the water is measured with the help of two RTD with temperature transmitter. The temperature and flow meter readings are recorded in a data logger. The vibration in the tank are measured with the help of offline vibration meter and dial gauge. 


\subsection{Construction of steam injector}

A steam injector consists of steam nozzle which injects steam into mixing chamber. The nozzles are made in different pattern for different sizes. The construction is summarized in the table 1 and Fig. 2.

Table 1[1]

\begin{tabular}{|c|c|c|c|}
\hline Steam Injector Size & $\begin{array}{l}\text { Size of steam } \\
\text { injection hole, } \mathrm{mm}\end{array}$ & Number of holes & $\begin{array}{l}\text { Position/arrangement } \\
\text { of holes }\end{array}$ \\
\hline $15 \mathrm{NB}$ & 6.2 & 1 & Central \\
\hline $25 \mathrm{NB}$ & 4.5 & 9 & circumferential \\
\hline $40 \mathrm{NB}$ & 7.6 & 8 & circumferential \\
\hline
\end{tabular}

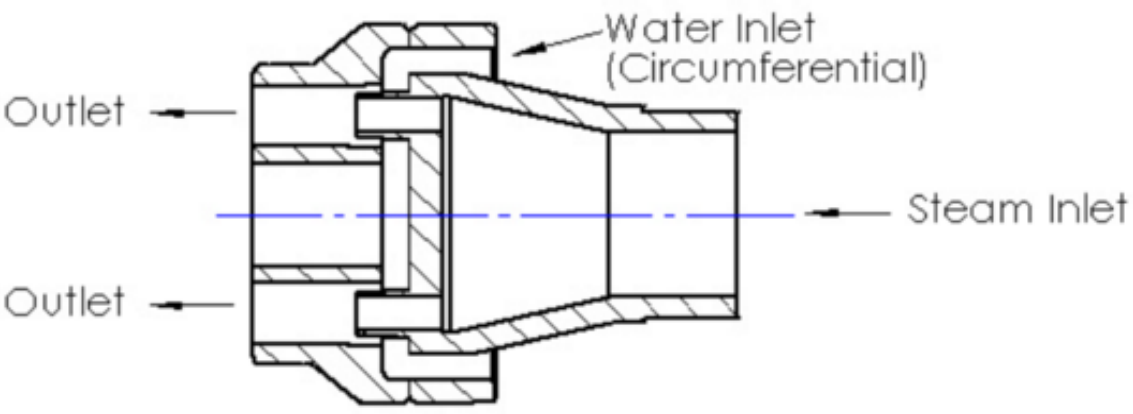

Fig. 2 Cross-section of steam Injector

\subsection{Experimental Results:}

The set of readings obtained for steam injector.

\section{1) 40 NB Steam Injector}

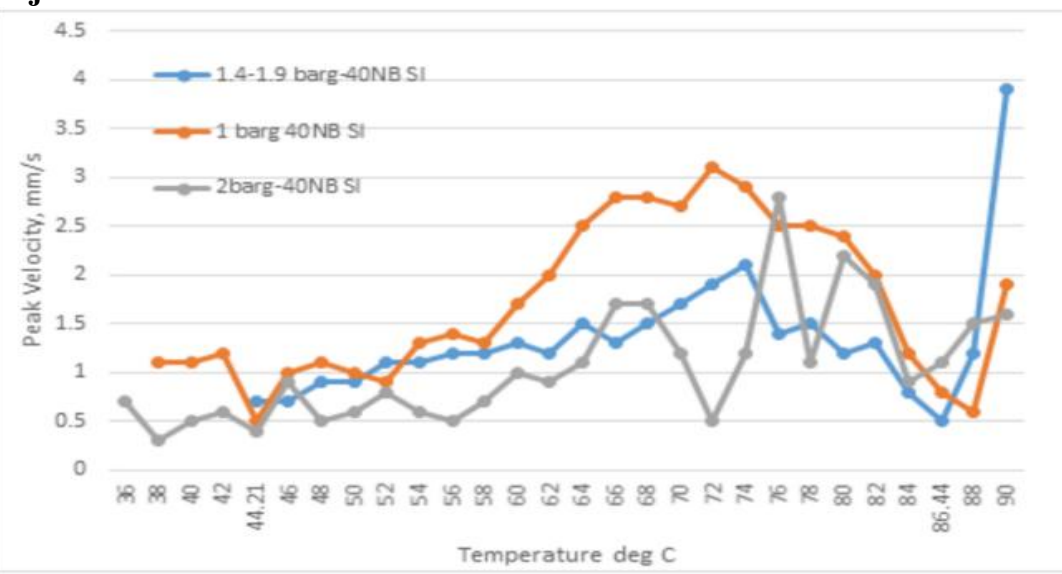

Fig. 3 (Comparison vibration for 40NB Steam Injector at different steam Pressures)

Fig. 3 shows the vibrations till water temperature of the $90^{\circ} \mathrm{C}$ measured by the accelerometer based vibration meter. The vibrations measured till $90^{\circ} \mathrm{C}$ were acceptable. The vibration meter was not able to measure vibrations above $90^{\circ} \mathrm{C}$ due to low frequency of vibrations. The vibrations above $90^{\circ} \mathrm{C}$ were measured with a dial gauge, it showed a peak displacement of $2 \mathrm{~mm}$ for steam pressure of $1 \mathrm{barg}$. This vibration is heavy vibration and is unacceptable. 
2) 40 NB Sparger:

The steam sparger was made for $40 \mathrm{NB}$ pipe with 8 hole of $8 \mathrm{~mm}$ diameter. The pitch to diameter ratio was 0.625. Fig. 4 shows the vibrations measured till the water temperature of $90^{\circ} \mathrm{C}$ again with the help of accelerometer based vibration. The vibrations reported above are acceptable. The operation of a sparger is noisy as compared with a steam injector. But above the $90^{\circ} \mathrm{C}$ heavy vibrations were experienced.

\section{3) 15 NB Steam Injector:}

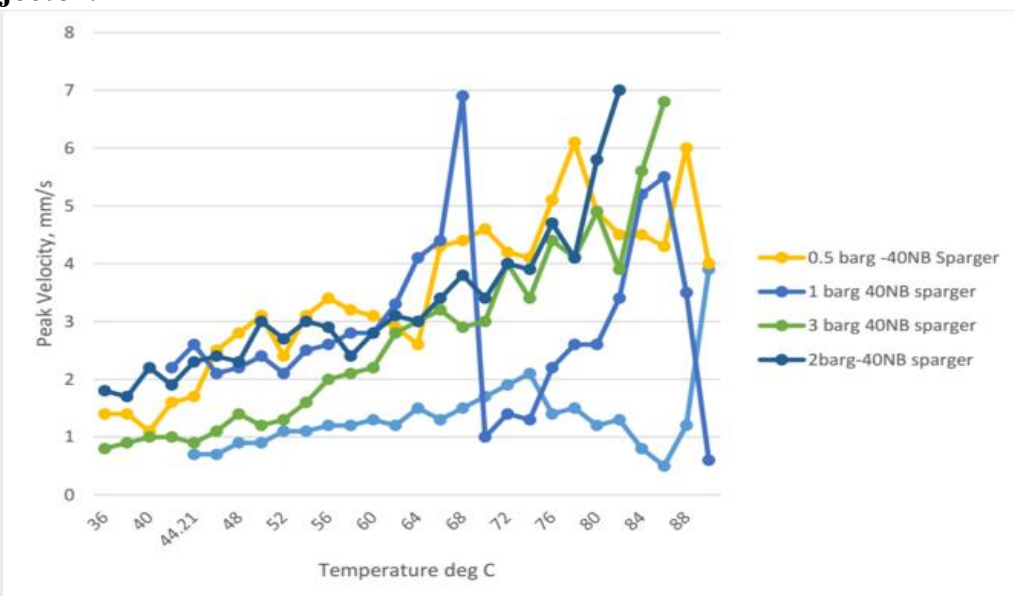

Fig. 4 (Comparison vibration for 40NB Steam Injector and Sparger) [2]

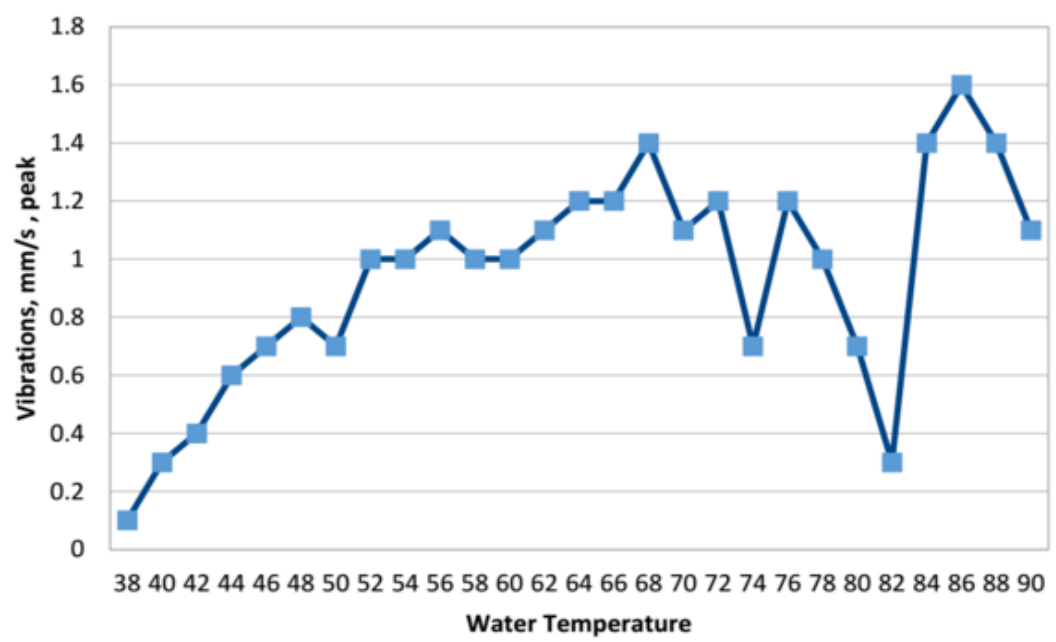

Fig.5 (Vibrations experienced in 15 NB steam Injector at 5 barg steam pressure)

For $15 \mathrm{NB}$ steam injector no vibrations were observed for the steam pressures of $1-6 \mathrm{barg}$ after $90^{\circ} \mathrm{C}$. The vibrations observed till $90^{\circ} \mathrm{C}$ are shown in figure 16 and are acceptable. No vibrations are present in the structure after $90^{\circ} \mathrm{C}$

\section{4) 25NB Steam Injector: [2]}

Figure 4.7 shows the vibrations obtained in the tank at steam pressure of 2 barg. The vibrations measured were within acceptable limit, till the water temperature of $90^{\circ} \mathrm{C}$.

\section{1) 25NB Steam spargers:}

Since the vibrations after $90^{\circ} \mathrm{C}$ were of more interest to us. The vibration measurement device was changed to dial gauge to measure vibrations. Two spargers with different geometrical configurations were tested.

1) Sparger with five holes of $6.2 \mathrm{~mm}$ hole diameter and p/d of 10: [2]. 2) Sparger with 26 holes of $5 \mathrm{~mm}$ diameter and $\mathrm{p} / \mathrm{d}$ of 4.67.Three reading were taken from a $25 \mathrm{NB}$ sparger with 26 holes of $5 \mathrm{~mm}$ diameter.

2) The results are shown in Table 3 . In both the cases the vibration were within the acceptable limit till water temperature of $90^{\circ} \mathrm{C}$. 


\section{Conclusion}

A vibration analysis of steam injector \& steam sparger showed that, steam injector gives fewer vibrations for the same pressured steam jets \& more homogeneous mixing of high pressure steam jet into the water as compared to steam sparger $\&$ hence is more preferable for heating of feed water in industries.

\section{1" SI 2barg- Vibrations}

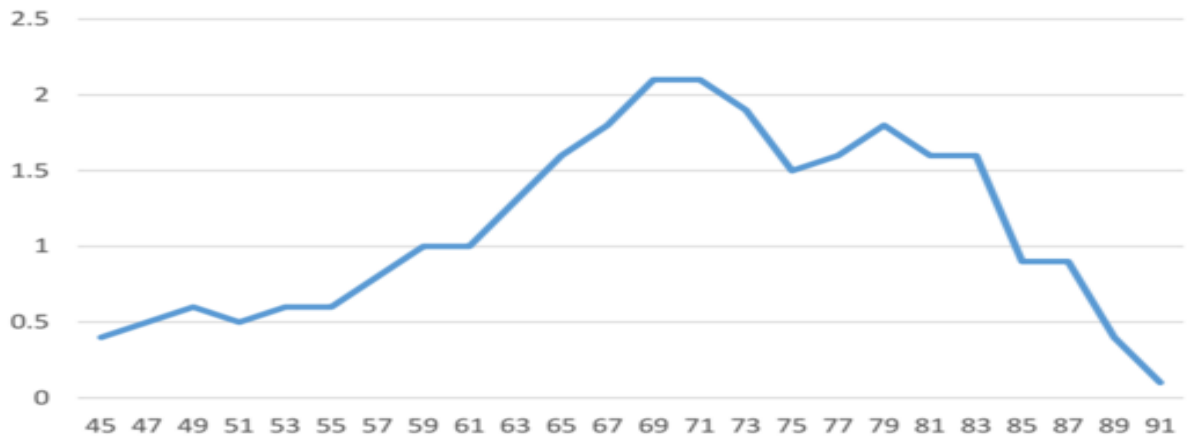

Fig.6 Pressure vs temperature

Table 2

\begin{tabular}{|c|c|c|}
\hline Steam Pressure & $2.8-3.5$ barg & 5.5 barg \\
\hline $\begin{array}{c}\text { Vibration } \\
\text { Measurement }\end{array}$ & Dial Gauge & Dial Gauge \\
\hline $\begin{array}{c}\text { Max } \\
\text { Vibrations(microns) }\end{array}$ & Plus Minus 20 & Plus Minus 25 \\
\hline Flow Rate(Kg/Hr) & 306 & 846 \\
\hline $\begin{array}{c}\text { Flow through each } \\
\text { hole(Kg/Hr) }\end{array}$ & 61.2 & No \\
\hline $\begin{array}{c}\text { Vibration (Visual) } \\
\text { Max Temperature }\end{array}$ & No & $99^{\circ} \mathrm{C}$ \\
\hline
\end{tabular}

Table 3

\begin{tabular}{|l|l|l|l|}
\hline Steam Pressure & 1 barg & 2 barg & 3 barg \\
\hline Vibration Measurement & Dial Gauge & Dial Gauge & Dial Gauge \\
\hline $\begin{array}{l}\text { Max } \\
\text { Vibrations(microns) }\end{array}$ & Plus Minus 10 & Plus Minus 10 & Plus Minus 10 \\
\hline Flow Rate(Kg/Hr) & 251 & 380 & 490 \\
\hline $\begin{array}{l}\text { Flow through each } \\
\text { hole(Kg/Hr) }\end{array}$ & 9.64 & 14.61 & 26 \\
\hline $\begin{array}{l}\text { Vibration (Visual) } \\
\text { Temperature reached, }{ }^{\circ} \mathrm{C}\end{array}$ & 99 & 99 & No(Allowable) \\
\hline
\end{tabular}

\section{Acknowledgements}

Authors express a deep sense of gratitude to Mr. Ameya Kulkarni for giving the opportunity to pursue project under his valuable guidance. They are thankful to him for his constant encouragement as well as for providing necessary information regarding the topic. The authors also acknowledge with thanks the support provided by Forbes Marshall. 


\section{References}

[1]. Forbes Marshall official web-site (https://www.forbesmarshall.com)

[2]. Spirax Sarco (www.spiraxsarco.com)

[3]. Armstrong International (https://www.armstronginternational.com)

[4]. TLV (www.tlv.com)

[5]. T. Bagatur, A. Baylar, N. Sekerdag, The effect of nozzle type on air entrainment byplunging water jets, Water Qual. Research Journal of Canada, 37(3),,2002,599-612.

[6]. H. Kim, et al., Experimental study on stable steam condensation in a quenching tank, International ournal of . Energy Research, 25, 2001, 239-252. 